\title{
Novel Antifungal Diketopiperazine from Marine Fungus
}

\author{
Hee-GuK Byun ${ }^{\mathrm{a}, *, \dagger}$, Huiping ZhanG ${ }^{\mathrm{a}}$, MASAmi MochizUKI ${ }^{\mathrm{a}}$, KyOKO AdACHI ${ }^{\mathrm{a}}$, \\ YoshiKaZU SHIZURI ${ }^{a}$, WON-JAE LEE ${ }^{b}$ and SE-KWON KIM ${ }^{c}$ \\ ${ }^{a}$ Marine Biotechnology Institute Co. Ltd., \\ Shimizu, Shizuoka 424-0037, Japan \\ ${ }^{b}$ Department of Microbiology, Pukyong National University, \\ Busan 608-737, Korea \\ ${ }^{\mathrm{c}}$ Department of Chemistry, Pukyong National University, \\ Busan 608-737, Korea
}

(Received for publication July 19, 2002)

\begin{abstract}
Marine fungi producing antifungal compounds were screened against Pyricularia oryzae (P. oryzae), and a metabolite of marine fungus M-3 isolated from laver (Porphyra yezoensis) showed potent activity. Novel diketopiperazine (1) was isolated from the culture extracts, and its structure was elucidated by spectroscopic methods. The MIC of 1 against $P$. oryzae was $0.36 \mu \mathrm{M}$.
\end{abstract}

Rice blast, caused by Pyricularia oryzae (P. oryzae), is generally considered to be the most serious fungal disease of rice because of its widespread distribution and destructiveness ${ }^{1)}$. The pathogenic fungus directly penetrates into the rice plant from a cellular structure called an appressorium formed at the tip of the germ tube. In addition, the fungus can attack any aerial part of the rice plant, including seeds, in which the fungus may overwinter for several years ${ }^{2}$. A continuous effort has been made to control this disease, especially by using fungicides ${ }^{3)}$ and breeding cultivars resistant to the disease ${ }^{4}$. However, these fungicides adversely effect the quality of the rice production and the environment. Moreover, breeding rice in consecutive use also causes differentiation of natural $P$. oryzae strains, which in turn cause the emergence of a new mutant.

Recently, pollution problems in the environment and the toxic effects of synthetic chemicals on non-target organisms have prompted investigations on exploiting pesticides of plant origin. Therefore, an environment-friendly method with biocontrol agents is recognized as an alternative approach to control rice blast ${ }^{5,6}$. The use of natural fungicides and biological control by antagonistic microorganisms are plausible ways to take this approach ${ }^{7}$. The fungicides such as taxol, vinblastin, griseofulvin, rhizoxin and flavonoids show a characteristic curling effect on mycelia of rice plant pathogenic fungus, $P$. oryzae, germinated in yeast extract solution ${ }^{8,9)}$. Even though several studies have reported the isolation of induced resistance in rice under laboratory conditions, demonstrations in the field are very limited.

In this study, extracts of marine fungi producing antifungal substances were screened for activity against $P$. oryzae. An active compound was identified and purified from culture broths of the marine fungus $M-3$, isolated from laver. Then the chemical structure of purified antifungal compound was elucidated by the spectroscopic methods.

\section{Materials and Methods}

\section{General}

UV-visible spectra were obtained on a Shimadzu UV$2100 \mathrm{~S}$ spectrometer. High performance liquid chromatography was carried out with Shimadzu LC8A system equipped with Shimadzu SPD-M6A photo diode array detector. NMR spectra were measured with a Varian

\footnotetext{
* Corresponding author: bhg@netian.com

† Present address: Department of Chemistry, Pukyong National University, 599-1 Daeyeon-dong, Nam-gu, Busan 608-737, Korea.
} 
UNITY500 NMR spectrometer. Mass spectra were recorded with a JEOL JMS-SX102 mass spectrometer. Optical rotation was determined with a Horiba SEPA-300 polarimeter. IR spectra were obtained with a JASCO FT-IR 7000 spectrophotometer.

\section{Isolation of Fungi from Laver}

Marine fungus M-3 was isolated from laver (Porphyra yezoensis) taken from the coast at Huttsu city, Chiba, Japan. A small piece of the laver was washed twice each with $2 \mathrm{ml}$ of sterilized $50 \%$ seawater containing $200 \mu \mathrm{g} / \mathrm{ml}$ of chloramphenicol in a sterilized test tube, and then steeped in the same solution $4 \mathrm{ml}$ for 24 hours in a sterilized plate. The plate was incubated at $20^{\circ} \mathrm{C}$ for 7 days, and mycelia were transferred to an agar plate (glucose $2 \%$, polypeptone $1 \%$, yeast extract $0.5 \%$, chloramphenicol $200 \mu \mathrm{g} / \mathrm{ml}$, penicillin $\mathrm{G} 50 \mu \mathrm{g} / \mathrm{ml}$ and agar $2 \%$ in $90 \%$ seawater, $\mathrm{pH} 6.5$ ). The agar plate was incubated at $20^{\circ} \mathrm{C}$, and the mycelia grown to the edge of plate was inoculated into a plate of $1 / 2$ potato dextrose agar (a half nutrient, $50 \%$ seawater).

\section{Fermentation, Purification of Antifungal Compound}

The seed culture of marine fungus was preformed by inoculating mycelial fragments of strain M-3 into $100-\mathrm{ml}$ Erlenmeyer flasks containing $30 \mathrm{ml}$ of $1 / 2$ potato dextrose medium at $20^{\circ} \mathrm{C}$ for 3 days. Five $\mathrm{ml}$ of this seed culture was transferred into each 1-liter Erlenmeyer flask containing $300 \mathrm{ml}$ of $1 / 2$ potato dextrose medium (total 3 liters) at $20^{\circ} \mathrm{C}$ for 21 days.

The culture broth ( 3 liters) was added to 3 liters of $80 \%$ $(\mathrm{v} / \mathrm{v})$ acetone, and then agitated using a magnetic stirrer for 1 hour at room temperature (Fig. 1). After the acetone extracts were clarified by centrifugation $(2,000 \times g, 15$ minutes) at $4^{\circ} \mathrm{C}$, and concentrated in vacuo, the resulting aqueous solution was extracted three times with 1 liter of ethyl acetate. The ethyl acetate extract was concentrated in vacuo.

The ethyl acetate extract was submitted to preparative TLC (PTLC) (glass plates, $0.5 \mathrm{~mm}$ silica gel $60 \mathrm{~F}_{254}$, Merck, Darmstadt, Germany). After development in hexane-acetone $(7: 3)$, the PTLC plate was divided into fourteen sections from top to bottom, which were scraped off the plate. TLC fractionates were eluted from the silica with chloroform-methanol $(1: 1)$ and the eluates were recovered by centrifugation $(850 \times g, 15$ minutes $)$. Dried fractions were dissolved in methanol and tested for antifungal activity using a 96-well micro-plate bioassay.

The active fraction obtained from the PTLC was further purified by reverse-phase HPLC (Develosil ODS-HG-5
Fig. 1. Isolation and purification scheme of antifungal compound $\mathbf{1}$.

\author{
Culture broth (3 liters) \\ Centrifuged $\left(2,000 \times \mathrm{g}, 15 \mathrm{~min}, 4^{\circ} \mathrm{C}\right)$ \\ Supernatant \\ $\mid \begin{aligned} & \text { Concentrated in vacuo } \\ & \text { Extracted with ethyl acetate }\end{aligned}$ \\ Ethyl acetate extract \\ Preparative TLC \\ Eluted with hexane-acetone (7:3) \\ Active fraction \\ Reverse-phase HPLC \\ Eluted with $70 \%(\mathrm{v} / \mathrm{v})$ methanol \\ Purified compounds $(0.8 \mathrm{mg})$
}

Added to 3 liters of $80 \%(\mathrm{v} / \mathrm{v})$ aq-acetone

column, i.d. $20 \times 250 \mathrm{~mm}$, Nomura Chemical Co., LTD., Japan). The column was eluted at a flow rate of $9 \mathrm{ml} /$ minute using $70 \%$ methanol, monitoring at $210 \mathrm{~nm}$. The antifungal activity of individual peaks was measured.

\section{Antifungal Assay}

The assay was performed by the method of KOBAYASHI et $a l .{ }^{8}$. P. oryzae was grown on a slant culture medium consisting of yeast extract $0.2 \%$, soluble starch $1 \%$ and agar $2 \%$ at $27^{\circ} \mathrm{C}$. The conidia were collected after 12 to 14 days of inoculation by suspending in sterilized water. The suspension was filtered to separate conidia from mycelia. To the filtrate was added a $2 \%$ solution of yeast extract, which was adjusted to the concentration of $0.02 \%$ yeast extract with sterilized water. For the quantitative estimation, an aliquot of the conidia suspension was taken on a microscope to count a number of conidia before adding yeast extract. The suspension was adjusted to $4 \times 10^{4}$ conidia/ml by adding sterilized water.

A 96-well micro-plate was used for the bioassay. Rhizoxin was used as the positive control with the final concentrations of $740 \mathrm{nM}, 250 \mathrm{nM}, 82 \mathrm{nM}, 27 \mathrm{nM}$ and $9 \mathrm{nM}$. One column of the 96-well micro-plate was used for one test material with eight different concentrations. The assay plates were incubated at $27^{\circ} \mathrm{C}$ for 16 hours, the shape of mycelia germinated from conidia was observed and compared with controls under an inverted Microscope (TMS, Nikon Co., Tokyo, Japan). 
Table 1. Antifungal activity against $P$. oryzae of fractions isolated by PTLC.

\begin{tabular}{ccccccccc}
\hline \multirow{2}{*}{ Fractions } & \multicolumn{7}{c}{ Concentration $(\mu \mathrm{g} / \mathrm{ml})$} \\
\cline { 2 - 8 } & 400 & 130 & 40 & 13 & 4 & 1.3 & 0.4 & 0.13 \\
\hline 1 & \pm & - & - & - & - & - & - & - \\
2 & +++ & + & \pm & - & - & - & - & - \\
3 & +++ & +++ & +++ & + & \pm & - & - & - \\
4 & + & \pm & - & - & - & - & - & - \\
5 & +++ & \pm & - & - & - & - & - & - \\
6 & +++ & ++ & + & \pm & - & - & - & - \\
7 & +++ & +++ & ++ & \pm & - & - & - & - \\
8 & +++ & ++ & + & \pm & - & - & - & - \\
9 & +++ & +++ & +++ & \pm & - & & - & - \\
10 & +++ & +++ & +++ & +++ & ++ & + & \pm & - \\
11 & +++ & +++ & +++ & + & \pm & - & - & - \\
12 & + & + & \pm & - & - & - & - & - \\
13 & + & \pm & - & - & - & - & - & - \\
14 & + & \pm & - & - & - & - & - & - \\
\hline
\end{tabular}

,,,++++++ \pm- levels were estimated by Kobayashi et al. (1996) method. MIC, minimum inhibitory concentration

The indices of hyphal growth inhibition used for quantitative estimations were divided into five classes $(-$, ,,\pm+++ , and +++ ) according to the length of mycelia germinated from conidia by KOBAYASHI et al. ${ }^{8)}$ method.

\section{Results and Discussion}

A preliminary antifungal screening was carried out to isolate 70 strains of marine fungi from several lavers and sponges. Only marine fungus $\mathrm{M}-3$ showed strong antifungal activity against this pathogenic fungus. The antifungal activity of extracts or fractions were determined using $P$. oryzae as the indicator organism in a 96-well micro-plate assay for inhibition of hyphal growth; minimum inhibitory concentration (MIC) values were calculated based on weight per volume $(\mu \mathrm{g} / \mathrm{ml})$. The positive control, rhizoxin, had an MIC of $27 \mathrm{nM}$.

The 18S rDNA sequence homology searches using the BLAST system corroborated the position of the strain M-3 within phylum Ascomycota. This strain has been deposited at the National Industrial Science and Technology of the Ministry of International Trade and Industry, Tsukuba-shi in Japan with accession number OEOM P-17709.
Table 2. Physico-chemical properties of antifungal compound 1.

\begin{tabular}{ll}
\hline Phase & Colorless solid \\
${ }^{*}[\alpha]_{\mathrm{D}}{ }^{25}$ & $-16^{\circ}$ \\
Molecular formula & $\mathrm{C}_{21} \mathrm{H}_{27} \mathrm{~N}_{3} \mathrm{O}_{2}$ \\
$\mathrm{FAB}-\mathrm{MS}(\mathrm{M}+\mathrm{H})^{+}$ & 354 \\
$\mathrm{UV} \lambda_{\max }{ }^{\mathrm{MeOH}} \mathrm{nm}$ & 222,288 \\
$\mathrm{IR} v_{\max }{ }^{\mathrm{BBr}} \mathrm{cm}^{-1}$ & $320(\mathrm{NH}), 2960,2925,2850,1670$, \\
\hline
\end{tabular}

The ethyl acetate extract from the culture broth of M-3 was concentrated in vacuo to obtain the dry yield $(86 \mathrm{mg})$. The extract was fractionated with PTLC glass plates. The PTLC fractions were divided into fourteen sections from top to bottom (fraction 1 to 14 ), which were scraped off the plate. Among the antifungal activity of the each PTLC fractions against $P$. oryzae, fraction $10(\mathrm{Rf}, 0.19)$ showed the highest activity at MIC value of $1.3 \mu \mathrm{g} / \mathrm{ml}$ (Table 1), and yield was $3.9 \mathrm{mg}$. The active fraction 10 obtained using 
Table 3. ${ }^{1} \mathrm{H}$ and ${ }^{13} \mathrm{C}$ NMR assignments for the antifungal compound 1 purified from M-3 culture broth.

\begin{tabular}{|c|c|c|}
\hline Positions & $\begin{array}{c}\text { Chemical shift (ppm)* } \\
{ }^{1} \mathrm{H} \delta(J / \mathrm{Hz})\end{array}$ & ${ }^{13} \mathrm{C} \delta$ \\
\hline $1(\mathrm{~N})$ & - & - \\
\hline 2 & $7.01 \mathrm{~s}$ & $126.83 d$ \\
\hline 3 & - & $108.14 \mathrm{~s}$ \\
\hline $3 a$ & - & $127.60 \mathrm{~s}$ \\
\hline 4 & $7.61 \mathrm{~d}(7.80)$ & $118.88 \mathrm{~d}$ \\
\hline 5 & 7.14 dd $(7.8,6.9)$ & $119.78 \mathrm{~d}$ \\
\hline 6 & $7.24 \mathrm{dd}(8.0,6.9)$ & $122.28 \mathrm{~d}$ \\
\hline 7 & $7.34 \mathrm{~d}(8.0)$ & $110.05 \mathrm{~d}$ \\
\hline $7 \mathrm{a}$ & - & $136.74 \mathrm{~s}$ \\
\hline \multirow[t]{2}{*}{8} & 3.00 dd $(14.5,10.5)$ & $31.11 \mathrm{t}$ \\
\hline & $3.70 \mathrm{dd}(14.5,3.2)$ & \\
\hline 9 & $4.30 \mathrm{dm}(10.5)$ & $55.31 \mathrm{~d}$ \\
\hline 10 & - & $166.52 \mathrm{~s}$ \\
\hline $11(\mathrm{NH})$ & $5.87 \mathrm{~s}$ & - \\
\hline 12 & $3.90 \mathrm{~m}$ & $60.48 \mathrm{~d}$ \\
\hline 13 & - & $167.84 \mathrm{~s}$ \\
\hline $14(\mathrm{NH})$ & $5.83 \mathrm{~s}$ & - \\
\hline 15 & $2.35 \mathrm{~m}$ & $31.51 \mathrm{~d}$ \\
\hline 16 & $0.90 \mathrm{~d}(6.6)$ & $16.35 \mathrm{q}$ \\
\hline 17 & $1.05 \mathrm{~d}(7.1)$ & $19.13 \mathrm{q}$ \\
\hline 18 & $4.67 \mathrm{~d}(6.8)$ & $44.43 \mathrm{t}$ \\
\hline 19 & $5.38 \mathrm{t}(6.8)$ & $119.78 \mathrm{~d}$ \\
\hline 20 & - & $136.74 \mathrm{~s}$ \\
\hline 21 & $1.85 \mathrm{~s}$ & $18.35 \mathrm{q}$ \\
\hline 22 & $1.80 \mathrm{~s}$ & $25.96 \mathrm{q}$ \\
\hline
\end{tabular}

PTLC was fractionated by reverse-phase HPLC. The MIC value of the compound 1 purified by HPLC was $0.13 \mu \mathrm{g} / \mathrm{ml}$, and the yield was $0.8 \mathrm{mg}$.

The structure of 1 was determined using IR, FAB-MS and NMR. The physicochemical properties of $\mathbf{1}$ are summarized in Table 2. In the IR spectrum, 1 showed multiple amide absorptions at 1670 and $1660 \mathrm{~cm}^{-1}$. These findings, in the absence of the amide II band near 1550 $\mathrm{cm}^{-1}$ suggest the presence of diketopiperazine system. Positive FAB-MS data demonstrated a molecular ion at $\mathrm{m} / \mathrm{z}$ $354\left([\mathrm{M}+\mathrm{H}]^{+}\right)$. High resolution FAB-MS $\left(m / z[\mathrm{M}+\mathrm{H}]^{+}\right)$: found, 354.2183; calculated, 354.2182) established the molecular formula as $\mathrm{C}_{21} \mathrm{H}_{27} \mathrm{~N}_{3} \mathrm{O}_{2}$.

The assignments of the ${ }^{1} \mathrm{H}$ NMR and ${ }^{13} \mathrm{C}$ NMR spectra were made on the basis of a standard COSY, HSQC and HMBC. The ${ }^{1} \mathrm{H}$ NMR and ${ }^{13} \mathrm{C}$ NMR chemical shifts of the compound are shown in Table 3. The chemical shifts and 2D-NMR data indicated 1 contained an indole ring and isoprenyl group. The chemical shifts of proton and carbon at $\mathrm{C}-18$ and its correlation to $\mathrm{C}-2$ in the HMBC suggest the
Fig. 2. The chemical structure of $\mathbf{1}$ purified from the M-3 metabolite.

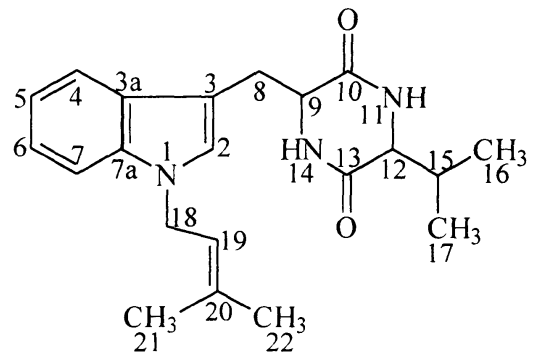

attachment of an isoprenyl group to the $\mathrm{N}$ atom in indole ring. The remaining protons are methylene $\left(\delta_{\mathrm{H}} 3.00\right.$ and 3.70), three methines $\left(\delta_{\mathrm{H}} 4.30,3.90\right.$, and 2.35) and two methyl groups $\left(\delta_{\mathrm{H}} 0.90,1.05\right)$. The carbonyl $\left(\delta_{\mathrm{C}} 166.52\right.$ and 167.84) carbons showed the long-range correlation with the above methines $\left(\delta_{\mathrm{H}} 4.30,3.90\right)$, suggesting a diketopiperazine structure. From these spectroscopic data, the structure was elucidated as the condensation product of $N$-isoprenyl-tryptophan and valine as shown in Fig. 2. The compound is (indole- $N$-isoprenyl)tryptophan-valine diketopiperazine, which elucidated a new member of a large class of well known fungal metabolites.

PEDras et al. ${ }^{10)}$ isolated a blackleg fungus, which caused lesions on leaves of canola, brown mustard, and wasabi (Eutrema wasabiae). The phytotoxic compound purified from the blackleg fungus was L-valyl-L-tryptophan anhydride; this compound lacks the $N$-linked isoprenyl group of 1 .

The antifungal compound $\mathbf{1}$ was soluble in acetone, ethyl acetate, chloroform, methanol and dimethylsulfoxide, but was insoluble in distillated water. The MIC value of the compound was $0.36 \mu \mathrm{M}$. Compound 1 inhibited the mycelial growth of $P$. oryzae by curling and swelling effect, and induced morphological changes of the mycelia. The results indicate that $\mathbf{1}$ may act via mechanisms similar to the antifungal mechanisms of rhizoxin, which is a commercial antifungicidal agent ${ }^{8)}$. Therefore, 1 purified from marine fungus M-3 may prove to be a valuable antifungicidal agent against rice blast disease.

\section{Acknowledgment}

This study was supported by Japan-Korea Industrial Technology Co-operation Foundation (JKF). I would like to 
thank researchers and staff in the Marine Biotechnology Institute (MBI) for their kind support and help. Thanks to Ms. KATO and other assistants, who gave kind help in experiments.

\section{References}

1) Manandhar, H. K.; H. J. Lyngs Jorgensen, S. B. Mathur \& V. SmedegaArd-Petersen: Suppression of rice blast by preinoculation with avirulent Pyricularia oryzae and the nonrice pathogen, Bipolaris sorokiniana. Phytopathology 88: 735 739, 1998

2) Manandhar, H. K.; H. J. Lyngs Jorgensen, V. SmedegaARd-Petersen \& S. B. Mathur: Seedborne infection of rice by Pyricularia oryzae and its transmission to seedlings. Plant Disease 82: 1093 1099, 1998

3) Bell, A. A. \& M. H. WheEler: Biosynthesis and functions of fungal melanin. Annu. Rev. Phytopathol. 24: 411 451, 1986

4) Bonman, J. M.; G. S. Khush \& R. J. Nelson: Breeding rice for resistance to pests. Annu. Rev. Phytopathol. 30: 507 528, 1992

5) KIM, Y. S.; J. K. Son, D. C. Moon \& S. D. KIM: Isolation and structure determination of antifungal antibiotics from Bacillus subtilis YB-70, a powerful biocontrol agent. Kor. J. Appl. Microbiol. Biotechnol. 25: 62 67, 1997

6) Lange, L.; J. Breinholt, F. W. Rasmussen \& R. I. NIELSEN: Microbial fungicides the natural choice. Pestic. Sci. 39: 155 160, 1993

7) Yeo, W. H.; S. K. KIM, S. S. KIM, S. H. Yu \& E. K. PARK: Isolation, physico-chemical properties, and biological activity of new thiopeptide antibiotics, kimorexins. J. Microbiol. Biotechnol. 4: 349 353, 1994

8) KoBayashi, H.; M. NAmikoshi, T. Yoshimoto \& T. YoKOCHI: A screening method for antimitotic and antifungal substances using conidia of Pyricularia oryzae, modification and application to tropical marine fungi. J. Antibiotics 49: 873 879, 1996

9) Padmavati, M.; N. Sakthivel, K. V. Thara \& A. R. REDDY: Differential sensitivity of rice pathogens to growth inhibition by flavonoids. Phytochemistry 46: 499 502, 1997

10) Pedras, M. S. C.; K. C. SMith \& J. L. Taylor: Production of 2,5-dioxopiperazine by a new isolated type of the blackleg fungus Phoma Lingam. Phytochemistry 49: $1575 \sim 1577,1998$ 